Article

\title{
Screening of New Microsatellite DNA Markers from the Genome of Platyeriocheir formosa
}

\author{
Hui-Ling Cheng ${ }^{1}$, Yan-Horn Lee ${ }^{2}$, Dai-Shion Hsiung ${ }^{3}$ and Mei-Chen Tseng ${ }^{3, *}$
}

1 Department of Environmental Resources Management, Chia Nan University of Pharmacy and Science, Tainan 717, Taiwan; E-Mail: lynn62359@mail.chna.edu.tw

2 Biotechnology Division, Fisheries Research Institute Council of Agriculture, Tungkang, Pingtung 928, Taiwan; E-Mail: leeyh4331@hotmail.com

3 Department of Aquaculture, National Pingtung University of Science and Technology, Pingtung 912, Taiwan; E-Mail: bear000000@yahoo.com.tw

* Author to whom correspondence should be addressed; E-Mail: mctseng@mail.npust.edu.tw; Tel.: +886-8-7703202 (ext. 6227); Fax: +886-8-7740401.

Received: 20 February 2012; in revised form: 22 April 2012 / Accepted: 24 April 2012 / Published: 9 May 2012

\begin{abstract}
The catadromous Platyeriocheir formosa is a crab endemic in Taiwan. To conserve $P$. formosa population diversity and ensure the sustainable use of this natural resource, we have developed new genetic markers, 17 polymorphic microsatellite loci, to promote the study of its population genetics in the future. In this study, more than 70 microsatellite sequences were found. Among these, 18 loci were selected to analyze the genetic diversity of $P$. formosa. With the exception of the Pfo15 locus, all of the remaining loci were polymorphic with allelic numbers ranging from 3-14. Heterozygosity within all 17 polymorphic loci ranged from $0.2-0.95$ with an average of 0.55 , which suggested that these loci are proper markers for studying population genetics. After we tested cross-specific amplification, eight and six primer sets could be successfully used for the amplification of microsatellite loci in morphologically similar Eriocheir sinensis and E. japonica, respectively; this suggests that they are useful markers for closely related species.
\end{abstract}

Keywords: catadromous; crab; cross-specific amplification; polymorphic loci 


\section{Introduction}

Platyeriocheir formosa, the unique species in the genus, is an endemic Taiwanese species of crab which is mainly distributed in rivers of eastern Taiwan [1] and which has a peculiar life history of spawning in the sea and growing up in rivers. The reproductive period of $P$. formosa is during spring and summer which greatly differs from morphologically similar Eriocheir species that spawn in winter. Eggs hatch into zoea which leave the female individual and begin a planktonic life in the sea. After passing through five ecdysis cycles, they metamorphose into megalopa that become submersed in an estuary until a second metamorphosis into juvenile crabs occurs [2]. In the summer, juvenile crabs move into rivers where they grow until adulthood. As the reproductive gland gradually matures, adults move from their habitats in middle and upstream reaches of rivers to coastal waters for mating and reproduction. The genetic diversity of $P$. formosa was analyzed using mitochondrial DNA cytochrome oxidase subunit I (COI) sequences, and results suggest that the species maintains high genetic polymorphism [3]. However, there was an insignificant genetic structure between samples from different streams. The primary reason was inferred to be a result of gene flow of $P$. formosa as their zoeal and megalopa stages disperse to different estuaries by ocean current transport.

Platyeriocheir formosa is a highly economic aquatic resource in Taiwan. Because the complete artificial culture of $P$. formosa has not yet succeeded, people catch large numbers of $P$. formosa from wild habitats and sell them. The wild population has to tolerate this intense artificial exploitation pressure. Unfortunately, when typhoon Morakot hit Taiwan in 2009, many rivers suffered severely, including mudflows that covered riverbeds which resulted in a significant decrease of population abundances of organisms such as $P$. formosa in rivers. It is clear that conservation work on $P$. formosa should be taken seriously. Because microsatellites have large mutation rates of $10^{-5}-10^{-2}$ per generation [4], they are widely used as markers for studying genetic mapping, population structure, kinship, evolutionary genetics, and genetic diseases [5-10]. For example, $\mathrm{Xu}$ and Liu developed microsatellite markers for the genetic analysis of the swimming crab, Portunus trituberculatus [11]. Microsatellite loci of the blue crab (Callinectes sapidus), the largest and most successful commercial and recreational fishery in Chesapeake Bay, USA [12], were cloned from the genome for forensic identification, pedigree analysis, and determination of the population structure [13].

To conserve $P$. formosa population diversity and ensure the sustainable use of this natural resource, the genetic structure and population dynamics must be determined. In this study, we developed new genetic markers, 17 polymorphic microsatellite loci, to promote the study of population genetics in the future.

\section{Results and Discussion}

Among about 2400 clones screened, 103 had positive signals. After sequencing, 97 different microsatellite sequences were determined including $70 \mathrm{GA} / \mathrm{GT}$ microsatellite sequences and 27 non-GA/GT components, e.g., TA, GC, and GGA repeats. Microsatellites were divided into three categories. For perfect microsatellites, the core region consists of tandem repeats. Tandem repeats interrupted by one or more additional or substituted nucleotides are called interrupted microsatellites. Compound repeated loci are composed of stretches of different repeated motifs [14]. In this study, all 
70 cloned GA/GT loci included 49 (70\%) perfect, 15 (21.4\%) interrupted, and six (8.6\%) compound microsatellite sequences, which suggested that the GA/GT microsatellites mainly consist of perfect repeat sequences in the genome of $P$. formosa. Total numbers of repeated motifs in the core region ranged from five to 45 for $(\mathrm{GA})_{\mathrm{n}}$ microsatellites and from five to 50 for $(\mathrm{GT})_{\mathrm{n}}$ microsatellites. Primers were designed for only 39 of the $70 \mathrm{GA} / \mathrm{GT}$ microsatellite sequences. The remaining microsatellites sequenced were not used due to the occurrence of a repeated site in one of the flanking regions, or because they were short. We tested various polymerase chain reaction (PCR) conditions with different concentrations of $\mathrm{MgCl}_{2}$, annealing temperatures, and numbers of PCR cycles. After resolution on 2\% agarose gels, 20 loci did not produce specific amplifications or were an inaccurate size; this was probably due to unfit primer design. However, we succeeded in testing the amplification of 19 loci that yielded consistent PCR products corresponding to a single locus of the expected size. One of the 19 loci (Pfo11) was monomorphic in all individuals screened. The Pfo15 locus was homozygous in all individuals. The remaining 17 loci have heterozygous genotypes. Primer sequences and PCR conditions of these polymorphic 18 loci that were correctly amplified are given in Table 1 . Allelic numbers within all 18 loci ranged from 3-14. The effective allelic number ranged from 2.25-10.26. Allelic sizes within these loci ranged from 68-239 bp. The allelic sizes of Pfo15, -31, and -34 were all shorter than $100 \mathrm{bp}$. When excluding the homozygous Pfo15 locus, the observed heterozygosity $\left(H_{\mathrm{O}}\right)$ ranged from $0.20-0.95$ with an average of 0.55 . The expected heterozygosity $\left(H_{\mathrm{E}}\right)$ ranged from 0.57-0.93 with an average of 0.818. Thirteen of these loci exhibited departure from Hardy-Weinberg (HW) equilibrium, which may suggest that $P$. formosa has a small effective population size, suffers an intense inbreeding effect or null allele effect or other possibilities. Burrow's composite measure for linkage disequilibrium (LD) among the 18 loci was estimated for the entire dataset. The total variance of interlocus allelic disequilibrium $\left(D_{\mathrm{IT}}^{2}=0.018\right)$ exhibited slight disequilibrium.

In contrast, a higher mean heterozygosity $\left(H_{\mathrm{O}}>0.8\right)$ was found in the marine swimming crab, Portunus trituberculatus [11], while a similar value of 0.55 was found in the catadromous crab, E. sinensis [15]. The mean allelic number per locus $(n a)$ in the catadromous $P$. formosa was estimated to be 9.61, which was lower than that of the marine Po. trituberculatus $(n a=22)$, but higher than that of $E$. sinensis on average $(n a=4.94)[11,15]$. These results agree with the observation that catadromous $P$. formosa have lower mean allelic numbers and genetic diversity than marine Po. trituberculatus species. Previous studies of microsatellite primers showed that they may be useful across a wide taxonomic range [16,17]. In this study, we also proved their cross-specific application as shown in Table 1. From these results, eight and six of the 18 microsatellite loci were successfully cross-amplified in E. sinensis and E. japonica, respectively. In the long-term pursuit of excellence in microsatellite studies of $P$. formosa, we provide a preliminary description of the characteristics of 18 novel microsatellite loci and their advantages as markers to study genetic diversity and population dynamics. 
Table 1. Primer sequences, characterization of the core region, and levels of genetic variation at 18 microsatellite loci from Platyeriocheir formosa.

\begin{tabular}{|c|c|c|c|c|c|c|c|c|c|c|c|}
\hline Locus & $\begin{array}{l}\text { Fluorescence } \\
\text { labeling }\end{array}$ & Primer sequence $\left(5^{\prime} \rightarrow 3^{\prime}\right)$ & $\begin{array}{l}\text { Major } \\
\text { repeats }\end{array}$ & $\begin{array}{c}T_{\mathrm{a}} \\
\left({ }^{\circ} \mathbf{C}\right)\end{array}$ & $\begin{array}{l}\text { Allelic size } \\
\text { range (bp) }\end{array}$ & $n a$ & ne & $H_{\mathrm{O}} / H_{\mathrm{E}}$ & $\begin{array}{r}\text { Cross species a } \\
\text { Eriocheir sinensis }\end{array}$ & $\begin{array}{l}\text { Implified For } \\
\text { E. japonica }\end{array}$ & $\begin{array}{c}\text { EMBL } \\
\text { Accession no. }\end{array}$ \\
\hline Pfo 4 & FAM & $\begin{array}{l}\text { F: TGTGAGACGGCGGTTACGAG } \\
\text { R: GAGCACTCTCCCTGGTCTTC }\end{array}$ & $(\mathrm{CA})_{29}$ & 56 & $145-183$ & 13 & 6.45 & $0.75 / 0.87$ & - & + & JQ582816 \\
\hline Pfo 5 & HEX & $\begin{array}{l}\text { F: TGTCCAACCGCTTTCTTTC } \\
\text { R: CGAAGATAACAGTAATACGG }\end{array}$ & $(\mathrm{TC})_{6}$ & 54 & $141-149$ & 3 & 2.25 & $0.55 / 0.57$ & - & + & JQ582817 \\
\hline Pfo 7 & HEX & $\begin{array}{l}\text { F: ACTAATCCAATGCCTGCC } \\
\text { R: CTATGCAGTCTCCTTCCGTAG }\end{array}$ & $(\mathrm{GT})_{22}$ & 52 & $217-239$ & 10 & 6.06 & $0.65 / 0.86$ & + & + & JQ582818 \\
\hline Pfo 9 & TAMRA & $\begin{array}{l}\mathbf{F}: \text { TCTAGGCTGCAGCTTCATAG } \\
\mathbf{R : G G A C G C A T T A G C A T A A C A ~}\end{array}$ & $(\mathrm{CA})_{31}$ & 54 & $156-194$ & 14 & 9.88 & $0.45 * / 0.92$ & + & + & JQ582819 \\
\hline Pfo10 & HEX & $\begin{array}{l}\text { F: TACCACGTCCGTTCTAG } \\
\text { R: CGTATAGGAGATTACTGG }\end{array}$ & $(\mathrm{CA})_{10}$ & 50 & $94-128$ & 8 & 7.27 & $0.65 / 0.88$ & - & - & JQ582820 \\
\hline Pfo12 & TAMRA & $\begin{array}{l}\text { F: TTCCTATCGCTCTCATCAGC } \\
\text { R: TTGTCCAGTTCATACTG }\end{array}$ & $(\mathrm{CA})_{32}$ & 56 & $186-216$ & 14 & 7.84 & $0.45 * / 0.89$ & + & - & JQ582821 \\
\hline Pfo15 & TAMRA & $\begin{array}{l}\text { F: GAAGAGTGTGGCGGAG } \\
\text { R: CTTGACACCTCGTGAGG }\end{array}$ & $(\mathrm{GT})_{16}$ & 60 & $68-76$ & 5 & 2.99 & $0.00 * / 0.68$ & + & - & JQ582822 \\
\hline Pfo18 & FAM & $\begin{array}{l}\text { F: GGAAGTGGTGGTAAAG } \\
\text { R: CACTTAACAGGTGGACA }\end{array}$ & $(\mathrm{CA})_{33}$ & 60 & $134-170$ & 13 & 6.84 & $0.35 * / 0.88$ & + & - & JQ582823 \\
\hline Pfo19 & FAM & $\begin{array}{l}\text { F: GGTGATCTTGGGCACCG } \\
\text { R: GATAGATACTTGAACACG }\end{array}$ & $(\mathrm{CA})_{32}$ & 50 & $141-175$ & 13 & 9.20 & $0.25 * / 0.91$ & - & - & JQ582824 \\
\hline Pfo31 & FAM & $\begin{array}{l}\text { F: GCACCACAGCGCTCTCTTAC } \\
\text { R: GGTAGGAAGACAGTGCG }\end{array}$ & $(\mathrm{CA})_{17}$ & 52 & 79-93 & 6 & 2.74 & $0.35 * / 0.65$ & - & + & JQ582825 \\
\hline Pfo34 & TAMRA & $\begin{array}{l}\text { F: GTAGAACTGACAGCC } \\
\text { R: CTGGTGCCTTACCTGTC }\end{array}$ & $(\mathrm{CA})_{20}$ & 50 & $71-77$ & 3 & 2.38 & $0.70 * / 0.59$ & - & - & JQ582826 \\
\hline Pfo36 & FAM & $\begin{array}{l}\mathbf{F}: \text { CTC GTTACTACACTCC } \\
\text { R: CCATTCATATGCCATG }\end{array}$ & $(\mathrm{CA})_{35}$ & 54 & $101-125$ & 10 & 6.11 & $0.50 * / 0.86$ & - & - & JQ582827 \\
\hline
\end{tabular}


Table 1. Cont.

\begin{tabular}{|c|c|c|c|c|c|c|c|c|c|c|c|}
\hline Pfo37 & TAMRA & $\begin{array}{l}\text { F: AAGCTGGCTGACACCTG } \\
\text { R: CGTCACCTTGCAATC }\end{array}$ & $(\mathrm{CA})_{31}$ & 50 & $166-200$ & 13 & 8.79 & $0.90 / 0.91$ & + & - & JQ582828 \\
\hline Pfo51 & FAM & $\begin{array}{l}\text { F: GTGCTCTGCGAAACG } \\
\text { R: GGAGTGCTGGAGTAG }\end{array}$ & $(\mathrm{CA})_{18}$ & 58 & 85-101 & 8 & 2.94 & $0.20 * / 0.68$ & - & - & JQ582829 \\
\hline Pfo52 & HEX & $\begin{array}{l}\text { F: GTATGTTGATGGCGTG } \\
\text { R: AGAGTGTGGCGGAGGC }\end{array}$ & $(\mathrm{CA})_{12}$ & 50 & 97-109 & 6 & 4.10 & $0.95 * / 0.78$ & - & - & JQ582830 \\
\hline Pfo54 & TAMRA & $\begin{array}{l}\text { F: GCATGCAAGAGCGTAG } \\
\text { R: TGACAGACAGACTCC }\end{array}$ & $(\mathrm{GT})_{18}$ & 50 & $141-173$ & 10 & 5.52 & $0.70 * / 0.84$ & + & - & JQ582831 \\
\hline Pfo60 & HEX & $\begin{array}{l}\mathbf{F}: \text { ACTATCACTAGGCTCAT } \\
\mathbf{R}: \text { TCAGTCTCGTATTCTC }\end{array}$ & $(\mathrm{GT})_{17}$ & 50 & $118-146$ & 11 & 7.62 & $0.55 * / 0.89$ & + & + & JQ582832 \\
\hline Pfo79 & FAM & $\begin{array}{l}\mathbf{F}: \text { TTATCCTGATCCTGAG } \\
\text { R: GACATAGCAGCAATAC }\end{array}$ & $(\mathrm{GT})_{26}$ & 52 & $113-143$ & 13 & 10.26 & $0.45 * / 0.93$ & - & - & JQ582833 \\
\hline
\end{tabular}

$T_{\mathrm{a}}$, polymerase chain reaction (PCR) annealing temperature; $n a$, observed number of alleles detected at each locus; ne, effective number of alleles; $H_{\mathrm{O}}$, observed heterozygosity within a sample; $H_{\mathrm{E}}$, expected heterozygosity within a sample. * significant Hardy-Weinberg deviation $(p<0.05)$. 


\section{Experimental Section}

\subsection{Sample Collection}

In total, 40 Platyeriocheir formosa specimens were collected in November 2010 from Jin-Luen, Taitung $\left(120^{\circ} 55^{\prime} \mathrm{E}, 22^{\circ} 32^{\prime} \mathrm{N}\right)$, southeastern Taiwan. The morphologically similar river crab, Eriocheir japonica, was collected from the Houlong River, in central Taiwan. Another economic exotic species of river crab, E. sinensis, was bought from an aquaculture farm in Pingtung, southern Taiwan.

\subsection{Genomic DNA Isolation}

Muscle tissues from all specimens were preserved in 95\% ethanol until DNA extraction. To obtain a large quantity of DNA for microsatellite library preparation, genomic DNA was isolated and purified from muscle tissues of one individual. Five hundred milligrams of tissues with $1 \mathrm{~mL}$ lysis buffer was digested with $55 \mu \mathrm{L}$ proteinase $\mathrm{K}$ solution-10 mM Tris- $\mathrm{HCl}$ (pH 8.0), $2 \mathrm{mM}$ ethylenediaminetetra-acetic acid (EDTA), $10 \mathrm{mM} \mathrm{NaCl}, 1 \%$ sodium dodecylsulfate (SDS), $10 \mathrm{mg} / \mathrm{mL}$ dithiothreitol (DTT), and $0.5 \mathrm{mg} / \mathrm{mL}$ proteinase K. DNA extraction was carried out using the method described in reference [18]. To quickly and conveniently purify small amounts of DNA from all specimens for the polymerase chain reaction (PCR), a Puregene core kit A (Qiagen, Valencia, CA, USA) was used in this study.

\subsection{Screening of GA/GT Microsatellite Sequences}

High-molecular-weight DNA from the genome DNA of one individual was digested with the AluI, HaeIII, and RsaI restriction enzymes (BioLabs, Ipswich, MA, USA) according to the manufacturer's instructions. Fragments of 200-800 nt were gel-purified using a GeneMark DNA Clean/Extraction Kit (Genemark Technology, Tainan, Taiwan) and inserted into the SmaI blunt site of pUC 18 (BioLabs). Recombinants carrying the fragments were transformed to a competent Escherichia coli DH5 $\alpha$ strain. The library was plated onto 2YT medium plates, and colonies were lifted onto Whatman filters. These plates were placed in an incubator until the colonies were restored. All filters were immersed in freshly prepared denaturing solution $(0.5 \mathrm{M} \mathrm{NaOH}$ and $1.5 \mathrm{M} \mathrm{NaCl})$ for $7 \mathrm{~min}$, twice in neutralizing solution (0.5 M Tris- $\mathrm{HCl}$ and $1.5 \mathrm{M} \mathrm{NaCl}$, at $\mathrm{pH} 8.0$ ) for $3 \mathrm{~min}$, and in $2-4 \times \mathrm{SSC}$ for $4 \mathrm{~min}$. They were then dried in an $80{ }^{\circ} \mathrm{C}$ oven for $1-2 \mathrm{~h}$ and preserved at $-20^{\circ} \mathrm{C}$ until hybridization. Before prehybridization, we washed these filters using a solution of $2 \times \mathrm{SSC}$ and $0.2 \% \mathrm{SDS}$. Prehybridization proceeded with hybridization buffer [19] for $1 \mathrm{~h}$ at $60{ }^{\circ} \mathrm{C}$. The probes used for hybridization were biotinylated oligo DNA $(\mathrm{GT})_{10}$ and $(\mathrm{GA})_{10}$. Hybridization was carried out overnight at $60^{\circ} \mathrm{C}$ using a hybridization oven.

After hybridization, filters were washed twice in primary washing buffer ( $1 \times \mathrm{SSC}$ and $0.2 \% \mathrm{SDS}$ ) at room temperature, washed once in secondary washing buffer $(0.5 \times \mathrm{SSC}$ and $0.2 \% \mathrm{SDS})$ at room temperature, and washed twice in $0.1 \times \mathrm{SSC}$ and $0.2 \% \mathrm{SDS}$ at $60{ }^{\circ} \mathrm{C}$. These filters were immersed in blocking solution (Amersham Biosciences, Piscataway, NJ, USA) for $30 \mathrm{~min}$ and then washed three times in TBS buffer $(0.05 \mathrm{M}$ Tris- $\mathrm{HCl}$ and $0.15 \mathrm{M} \mathrm{NaCl}$, at $\mathrm{pH} 7.5)$ for $10 \mathrm{~min}$. The filters were incubated in $10 \mathrm{~mL}$ TBS buffer with $2 \mu \mathrm{L}$ streptavidin-alkaline phosphatase $(1 \mathrm{mg} / \mathrm{mL})$ and $0.05 \%$ Tween 20 and then washed three times in TBS buffer for $10 \mathrm{~min}$ each. Deep-blue colonies were 
visualized by immersion in an NBT/BCIP solution for $1 \mathrm{~h}$. Positive clones were sequenced on an Applied Biosystems automated DNA sequencer 377 vers. 3.3 (ABI, Foster City, CA, USA) using a Bigdye sequencing kit (PE Applied Biosystems, Foster City, CA, USA).

\subsection{Genotyping and Analysis}

Paired primers of 15-21 nt long were designed using DNASTAR Primer Select software (vers. 4.0) (DNASTAR, Madison, WI, USA) for the 39 clones containing perfect repeat sequences. A PCR was performed in a volume of $25 \mu \mathrm{L}$ including $\sim 10 \mathrm{ng}$ genomic DNA, 10 pmol of the reverse primer, 10 pmol of the forward primer, $25 \mathrm{mM}$ dNTP, 0.05-0.1 $\mathrm{mM} \mathrm{MgCl}_{2}, 10 \times$ buffer, and $0.5 \mathrm{U}$ Taq polymerase (Takara Shuzo, Tokyo, Japan) with Milli-Q water. The PCR products were subjected to a $1.5 \%$ agarose gel, and allelic sizes were checked by comparison with a DNA ladder and the length of the original sequence. Forward primers were labeled with FAM, TAMRA, and HEX fluorescence markers. PCR amplifications were carried out in a Px2 Thermal Cycler (Thermo Fisher Scientific, Waltham, MA, USA) with the following temperature profile: 1 cycle of $95^{\circ} \mathrm{C}$ for $4 \mathrm{~min}$, followed by 38 cycles of $94{ }^{\circ} \mathrm{C}$ for $30 \mathrm{~s}$ and annealing at $52-60{ }^{\circ} \mathrm{C}$ for $30 \mathrm{~s}$ and $72{ }^{\circ} \mathrm{C}$ for $30 \mathrm{~s}$. Each $5 \mu \mathrm{L}$ of PCR product from three loci labeled with the different fluorescence tags was mixed and precipitated with 95\% alcohol. Semiautomated genotyping was performed using a capillary ABI 3730XL DNA Analyzer (ABI). Genotypes were scored with GeneMapper 4.0 (ABI).

The total number of alleles $(n a)$ and effective allelic numbers were estimated for each locus using the program, Popgene [20]. Observed $\left(H_{\mathrm{O}}\right)$ and expected $\left(H_{\mathrm{E}}\right)$ heterozygosities were independently calculated for each locus [21]. Deviations from Hardy-Weinberg expectations (HWEs) were examined by an exact test using GENEPOP [22]. Linkage disequilibrium among all pairs of loci was determined using Burrow's composite measure and $\chi^{2}$ values [23].

\section{Conclusions}

In conclusion, 18 out of 39 primer sets can successfully amplify microsatellite loci in $P$. formosa. The polymorphism of genetic variations suggested that these loci are proper genetic markers for addressing questions of population genetics and population dynamics of $P$. formosa in the future. In addition, we also tested the close related species and found that there are eight and six primer sets which can be used successfully for E. sinensis and E. japonica, respectively.

\section{Acknowledgments}

We are extremely grateful to YH Hung for her help with laboratory work.

\section{References}

1. Chan, T.Y.; Hung M.S.; Yu, H.P. Identity of Eriocheir recta (Stimpson, 1858) (Decapoda: Brachyura), with description of a new mitten crab from Taiwan. J. Crust. Biol. 1995, 15, 301-308.

2. Shy, J.Y.; Yu, H.P. Complete larval development of the mitten crab Eriocheir rectus Stimpson, 1858 (Decapoda, Brachyura, Grapsidae) reared in the laboratory. Crustaceana 1992, 63, 277-290. 
3. Shiao, C.Y. The Genetic Diversity of Eriocheir formosa (Crustacea, Decapoda, Grapsidae). Master Thesis, Department of Life Science, National Tsing Hua University, Hsinchu, Taiwan, 2007.

4. Weber, J.L.; Wong, C. Mutation of human short tandem repeats. Hum. Mol. Genet. 1993, 2, 1123-1128.

5. Baranski, M.; Moen, T.; Våge, D.I. Mapping of quantitative trait loci for flesh colour and growth traits in Atlantic salmon (Salmo salar). Genet. Sel. Evol. 2010, 42, doi:10.1186/1297-9686-42-17.

6. Malausa, T.; Dalecky, A.; Ponsard, S.; Audiot, P.; Streiff, R.; Chaval, Y.; Bourguet, D. Genetic structure and gene flow in French populations of two Ostrinia taxa: Host races or sibling species? Mol. Ecol. 2007, 6, 4210-4222.

7. Pilot, M.; Dabrowski, M.J.; Jancewicz, E.; Schtickzelle, N.; Gliwicz, J. Temporally stable genetic variability and dynamic kinship structure in a fluctuating population of the root vole Microtus oeconomus. Mol. Ecol. 2010, 19, 2800-2812.

8. Gottelli, D.; Sillero-Zubiri, C.; Applebaum, G.D.; Roy, M.S.; Girman, D.J.; Garcia-Moreno, J.; Ostrander, E.A.; Wayne R.K. Molecular genetics of the most endangered canid: The Ethiopian wolf Canis simensis. Mol. Ecol. 1994, 3, 301-312.

9. Viard, F.; Bremond, P.; Labbo, R.; Justy, F.; Delay, B.; Jarne, P. Microsatellites and the genetics of highly selfing populations in the freshwater snail Bulinus truncates. Genetics 1996, 142, $1237-1247$.

10. Pinheiro, M.; Ahlquist, T.; Danielsen, S.A.; Lind, G.E.; Veiga, I.; Pinto, C.; Costa, V.; Afonso, L.; Sousa, O.; Fragoso, M. Colorectal carcinomas with microsatellite instability display a different pattern of target gene mutations according to large bowel site of origin. BMC Cancer 2010, 10, doi:10.1186/1471-2407-10-587.

11. Xu, Q.; Liu, R. Development and characterization of microsatellite markers for genetic analysis of the swimming crab, Portunus trituberculatus. Biochem. Genet. 2011, 49, 202-212.

12. Cronin, L.E. Early days of crabbing and a brief history for the Chesapeake Bay. J. Shellfish Res. 1998, 17, 379-382.

13. Steven, C.R.; Hill, J.; Masters, B.; Place, A.R. Genetic markers in blue crabs (Callinectes sapidus) I: Isolation and characterization of microsatellite markers. J. Exp. Mar. Biol. Ecol. 2005, 319, 3-14.

14. Weber, J.L. Informativeness of human $(\mathrm{dC}-\mathrm{dA})_{n}$. (dG-dT) $)_{n}$ polymorphisms. Genomics 1990, 7 , 524-530.

15. Gao, X.G.; Li, H.J.; Li, Y.F.; Sui, L.J.; Zhu, B.; Liang, Y.; Liu, W.D.; He, C.B. Sixteen polymorphic simple sequence repeat markers from expressed sequence tags of the Chinese mitten crab Eriocheir sinensis. Int. J. Mol. Sci. 2010, 11, 3035-3038.

16. Tseng, M.C.; Chen, C.A.; Kao, H.W.; Tzeng, W.N.; Lee, S.C. Polymorphisms of GA/GT microsatellite loci from Anguilla japonica. Mar. Biotechnol. 2001, 3, 275-280.

17. Jean, C.T.; Lee, S.C.; Liu, C.W.; Tseng, M.C. Isolation and characterization of eight microsatellite loci from Picnic seabream (Acanthopagrus berda) Mol. Ecol. Notes 2006, 6, 1269-1271.

18. Kocher, T.D.; Thomas, W.K.; Meyer, A.; Edwards, S.V.; Paabo, S.; Villablabca, F.X.; Wilson, A.C. Dynamics of mitochondrial DNA evolution in animals: Amplification and sequencing with conserved primers. Proc. Natl. Acad. Sci. USA 1989, 86, 6196-6200. 
19. Sambrook, J.; Fritsch, E.F.; Maniatis, T. Molecular Cloning: A Laboratory Manual, 2nd ed.; Cold Spring Harbor Laboratory Press: Cold Spring Harbor, NY, USA, 1989.

20. Yang, R.C.; Yeh, F.C. Multilocus structure in Pinus contoria Dougl. Theor. Appl. Genet. 1993, $87,568-576$.

21. Raymond, M.; Rousset, F. An exact test for population differentiation. Evolution 1995, 49, 1280-1283.

22. Rousset, F. Genepop'007: A complete reimplementation of the Genepop software for Windows and Linus. Mol. Ecol. Res. 2008, 8, 103-106.

23. Ohta, T. Linkage disequilibrium due to random drift in infinitely subdivided populations. Proc. Natl. Acad. Sci. USA 1982, 79, 1940-1944.

(C) 2012 by the authors; licensee MDPI, Basel, Switzerland. This article is an open access article distributed under the terms and conditions of the Creative Commons Attribution license (http://creativecommons.org/licenses/by/3.0/). 